\title{
A keratinised lump on the lateral surface of the tongue
}

\section{Camile S Farah}

CASE

A female patient, aged 59 years, presents with an $8 \mathrm{~mm}$ slightly raised lump on the right lateral border of the tongue (Figure 1) that has been present for one week. Her medical history is significant for hyperlipidaemia, and she is taking rosuvastatin $10 \mathrm{mg}$ daily. The patient does not smoke and consumes 2-3 standard alcoholic drinks per week. The medical practitioner arranges an urgent referral to an oral medicine specialist as the patient's teeth are rubbing on the lump.

The patient states that she had bitten her tongue prior to noticing the lesion. On clinical examination, the lesion presents as a non-homogeneous white patch with a slightly raised margin, particularly along its posterior border. On palpation, the lesion is hard to touch and appears tethered to underlying muscle.

\section{QUESTION 1}

What is the differential diagnosis that should be considered?

\section{QUESTION 2}

What is the most likely diagnosis?

\section{QUESTION 3}

How does the diagnosed condition typically present?

\section{QUESTION 4}

What risk factors exist for this condition?

\section{QUESTION 5}

What diagnostic tests need to be undertaken to confirm the diagnosis?

\section{QUESTION 6}

What management is required for this condition?

\section{QUESTION 7}

What factors are important for improving patient prognosis?

\section{ANSWER 1}

Given the patient reports that she bit her tongue before noticing the lesion, a traumatic aetiology should be considered first. However, acutely traumatic lesions in the mouth would generally present as an ulcerated lesion, not a thick, white keratinising patch. Chronic traumatic lesions such as traumatic ulcerative granuloma with stromal eosinophilia in the mouth may present with surface keratinisation and should be included in the differential diagnosis of this lesion. A potentially malignant oral lesion such as oral leukoplakia (with or without dysplasia) is also a likely diagnosis given the non-homogeneous white presentation and the lack of any symptoms. ${ }^{1}$

\section{ANSWER 2}

The likely diagnosis is oral squamous cell carcinoma (OSCC) given the presence of induration (lesion is hard on palpation) and fixation (lesion is tethered to underlying tongue musculature), despite the clinical visual appearance of a white patch/lump. ${ }^{2}$

\section{ANSWER 3}

OSCC does not have one typical clinical presentation, which makes its definitive diagnosis difficult. ${ }^{2}$ Lesions may present as an indurated fixed lump, a necrotic lesion, a white plaque, an exophytic mass or a chronic ulcer. Early lesions may only demonstrate a white or mixed red/white appearance (leukoplakia/erythroleukoplakia) or, rarely, a solitary red lesion (erythroplakia). More advanced lesions may have raised rolled margins and central necrosis, and are typically larger in size. ${ }^{2}$

\section{ANSWER 4}

Traditional risk factors for OSCC include older age, male gender, tobacco smoking and excessive alcohol consumption. ${ }^{2}$ Oral hygiene status, local trauma and chronic inflammation are thought to play very minor, if any, roles in the initiation of OSCC. Human papillomavirus is an aetiological factor in a small number (between $5 \%$ and $8 \%$ ) of OSCC cases, ${ }^{3}$

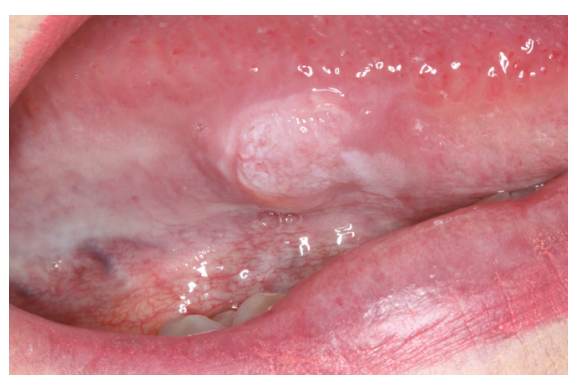

Figure 1. A non-homogeneous white keratinised lump on the right lateral border of the tongue 
compared with its significant role in the aetiology of oropharyngeal (throat) squamous cell carcinoma (SCC). In recent years, there has been an increase in OSCC diagnosed in younger patients (aged $<45$ years) with minimal or no traditional risk factors. ${ }^{4}$

\section{ANSWER 5}

Clinical assessment (visual and palpation) as part of a comprehensive head and neck cancer examination is mandatory. This can be undertaken with the assistance of optical adjunctive devices such as autofluorescence or narrow-band endoscopy, but it should always be undertaken with high-quality white light illumination and preferably under magnification. ${ }^{2}$ Computed tomography (CT) scanning with contrast of the head and neck should be undertaken. ${ }^{5}$ Tongue lesions can also be assessed with magnetic resonance imaging or ultrasonography for determination of lesion depth. CT of the chest should also be undertaken for smokers. Positronemission tomography is used for staging to determine distant metastases. Finally, incisional biopsy of an adequate size and depth is mandatory for histopathological definitive diagnosis. ${ }^{2}$ Assessment of imaging and histopathology by experts in head and neck imaging and oral and maxillofacial pathology assists in improving patient outcomes.

\section{ANSWER 6}

Early and small (Stage I and II) tumours typically undergo wide local excision or resection with no requirement for reconstruction. More extensive (Stage III and IV) tumours require wider/deeper resection, often with reconstruction depending on location. ${ }^{2}$ Neck dissection is often required in later disease, but selective neck dissection or sentinel lymph node biopsy can be used for $\mathrm{T} 1 / \mathrm{T} 2$ tumours given the possibility of occult metastasis. Depending on TNM staging, ${ }^{6}$ post-operative radiotherapy can be used to improve outcomes. Chemoradiotherpy is typically not used for OSCC. ${ }^{7}$ In contrast, p16-positive SCC of the oropharynx can be treated with radiotherapy or immunotherapy.

\section{ANSWER 7}

The most important prognostic factor for OSCC is tumour stage at diagnosis. In Australia, the five-year overall survival rate ranges from $25 \%$ to $85 \%$ depending on disease stage. ${ }^{8}$ Reducing diagnostic and treatment delay is important for improving patient outcomes. OSCCs double in size every three months, ${ }^{9}$ so it is imperative that general practitioners initiate appropriate referral pathways for suspected OSCC. The use of new optical and surgical approaches can improve disease-free survival ${ }^{10}$ and reduce the economic burden of OSCC, ${ }^{11}$ but early diagnosis remains the primary prognostic factor.

\section{CASE CONTINUED}

The patient is assessed with optical fluorescence imaging and narrow-band endoscopy, which show features consistent with oral malignancy. CT scans of the head and neck show an $8 \mathrm{~mm} \times 6 \mathrm{~mm} \times 5 \mathrm{~mm}$ enhancing lesion in the right lateral tongue, with no suspicious cervical lymphadenopathy. The lesion is locally excised, with margins determined by fluorescence and narrow-band endoscopy. Histopathology shows a well-differentiated keratinising SCC. The patient is followed-up on a three-monthly basis, and remains disease free two years after excision.

\section{Key points}

- Early diagnosis and appropriate referral pathways are primary considerations for improving patient outcomes with oral cancer.

- Early oral cavity SCC can present as a white, red or mixed red/white lesion, while late disease typically presents as a chronic ulcer, exophytic growth or indurated mass.

- Although traditional risk factors such as tobacco smoking and excessive alcohol consumption, particularly for older males, are important to note in high-risk patients, OSCC should also be suspected in younger patients without traditional risk factors.

\section{Author}

Camile S Farah BDSc, MDSc (OralMed OralPath), PhD, GCEd (HE), GCExLead, MAICD, AFCHSM, FRACDS (OralMed), FOMAA, FIAOO, FICD, FPFA FAIM, Registered Specialist in Oral Medicine and Oral Pathology, Director, Australian Centre for Oral Oncology Research and Education, WA; Oral Medicine Specialist, Perth Oral Medicine and Dental Sleep Centre, WA; Consultant in Oral Medicine, Fiona Stanley Hospital, WA; Consultant Oral Pathologist, Australian Clinical Labs, WA; Consultant Oral Pathologist, Qscan Radiology Clinics, WA; Chief Scientific Officer, Genomics for Life, Qld. camile@oralmedpath.com.au

Competing interests: None.

Funding: None.

Provenance and peer review: Not commissioned, externally peer reviewed.

\section{References}

1. Jessri M, Mawardi H, Farah CS, Woo SB. White and red lesions of the oral mucosa. In: Farah CS, Balasubramaniam R, McCullough MJ, editors. Contemporary oral medicine. Cham, $\mathrm{CH}$ : Springer International Publishing, 2019; p. 1207-48.

2. Farah CS, Kujan O, Prime S, Zain RB. Oral mucosal malignancies. In: Farah CS, Balasubramaniam R, McCullough MJ, editors. Contemporary oral medicine. Cham, CH: Springer International Publishing, 2019; p. 1249-436.

3. Lingen MW, Xiao W, Schmitt A, et al. Low etiologic fraction for high-risk human papillomavirus in oral cavity squamous cell carcinomas. Oral Oncol 2013;49(1):1-8. doi: 10.1016/j. oraloncology.2012.07.002.

4. $\mathrm{Ng} \mathrm{JH}$, lyer NG, Tan MH, Edgren G. Changing epidemiology of oral squamous cell carcinoma of the tongue: A global study. Head Neck 2017;39(2):297-304. doi: 10.1002/hed.24589.

5. Whyte A, Boeddinghaus R, Matias MATJ. Diagnostic imaging principles and applications in head and neck pathology. In: Farah CS, Balasubramaniam R, McCullough MJ, editors. Contemporary oral medicine. Cham, CH: Springer International Publishing, 2019; p. 173-253.

6. Pollaers K, Hinton-Bayre A, Friedland PL, Farah CS. AJCC 8th Edition oral cavity squamous cell carcinoma staging - Is it an improvement on the AJCC 7th Edition? Oral Oncol 2018;82:23-28. doi: 10.1016/j.oraloncology.2018.04.018.

7. Crombie AK, Farah CS, Batstone MD. Healthrelated quality of life of patients treated with primary chemoradiotherapy for oral cavity squamous cell carcinoma: A comparison with surgery. Br J Oral Maxillofac Surg 2014;52(2):111-17. doi: 10.1016/j.bjoms.2013.09.014.

8. Webster JD, Batstone M, Farah CS. Missed opportunities for oral cancer screening in Australia. J Oral Pathol Med 2019;48(7):595-603. doi: 10.1111/jop.12915.

9. Jensen AR, Nellemann HM, Overgaard J. Tumor progression in waiting time for radiotherapy in head and neck cancer. Radiother Oncol 2007;84(1):5-10. doi: 10.1016/j.radonc.2007.04.001.

10. Farah CS. Narrow band imaging-guided resection of oral cavity cancer decreases local recurrence and increases survival. Oral Dis 2018;24(1-2):89-97. doi: 10.1111/odi.12745.

11. Pollaers K, Massingham I, Friedland PL, Farah CS. The economic burden of oral squamous cell carcinoma in Australia. J Oral Pathol Med 2019;48(7):588-94. doi: 10.1111/jop.12907.

correspondence ajgp@racgp.org.au 